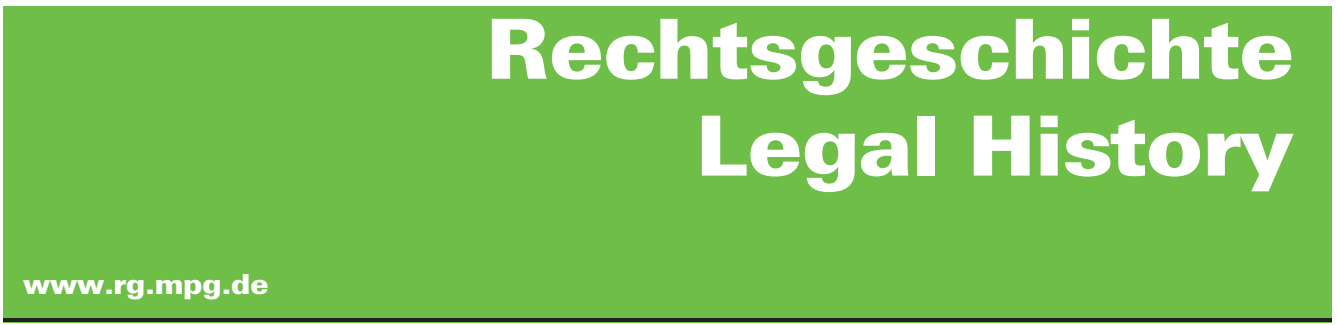

http://www.rg-rechtsgeschichte.de/rg20

$\operatorname{Rg} 202012 \quad 309-327$

Zitiervorschlag: Rechtsgeschichte - Legal History Rg 20 (2012)

http://dx.doi.org/10.12946/rg20/309-327

\title{
María Rosario Polotto
}

\section{Argumentación jurídica y trasfondo ideológico}

Análisis del debate legislativo sobre prórroga de alquileres en argentina a principios del siglo xx 
El presente trabajo aborda el debate parlamentario de las leyes 11.152 y 11.157 , que intentaron brindar una solución legislativa al problema habitacional que en ese momento atravesaba nuestro país. La hipótesis de nuestra investigación plantea que lejos de buscar en las discusiones conceptos cerrados o rígidos, las referencias a nociones como código, derecho, propiedad, libertad de contratar, derecho extranjero, nos remiten a lugares de discusión desde donde se argumentan las disímiles posturas suscitadas frente a las medidas proyectadas. Creemos que una fuente privilegiada donde es posible rescatar las múltiples significaciones de nuestras instituciones jurídicas y sus trasfondos ideológicos, lo constituyen los debates parlamentarios. En efecto, se ha visto en los parlamentos, una «asamblea de los representantes de los principales puntos de vista en conflicto en la sociedad», conduciendo sus «deliberaciones y toma de sus decisiones en el marco del conflicto y la controversia sobre los mismos» y creando derecho «sobre la base de las convicciones y los votos explícitamente partidistas de sus miembros». En este contexto, el derecho ya no sería entidad abstracta y aséptica, lógica en sus consecuencias, sino más bien tópico, argumentación jurídica de un cierto posicionamiento ideológico, frente a las circunstancias fácticas de una determinada sociedad. Una arista peculiar de nuestro análisis es el derecho extranjero como tópico. Nuestra mirada, más que simplificar, intentará acercarse a la complejidad de los procesos de circulación de ideas jurídicas y seguimiento de modelos jurídicos europeos que gravitaron sobre las élites argentinas durante la primera mitad del siglo XX.

\section{Abstract}

This article pretends to deal with the parliamentary discussion of the laws 11.152 and 11.157 that intended to bring a legislative solution to the habitual problem that Argentina was going through at that moment. The hypothesis of our investigation is that, far from trying to find closed or rigid concepts in those debates, the reference to notions such as code, right, property, freedom to hire, foreign law, takes us to areas of discussion from which different opinions on the measures taken can be formed. We think that a privileged source from which it is possible to rescue the multiple meanings of our juridical institutions and their ideological backgrounds are the parliamentary debates. Therefore, parliaments are seen as an "assembly of the representatives of the main points of view which are found in society«, taking their »deliberations and decisions to the frame of the conflict and the controversy on those views" and creating law »on the basis of convictions and votes explicitly partisan«. In this context, the law is no longer an abstract and neutral entity, logical in its consequences, but a topic, a juridical argumentation of a certain ideological position, dealing with the factual circumstances of a certain society. A particular aspect of this analysis is Foreign Law as a topic. Our point of view stresses that rather than seek to simplify, we should try to understand the complexity of the circulation processes of juridical ideas and the adoption of European juridical models that were in the mind of the Argentinian elites during the first half of the 20th century. 


\section{María Rosario Polotto}

\section{Argumentación jurídica y trasfondo ideológico}

Análisis del debate legislativo sobre prórroga de alquileres en argentina a principios del siglo $\mathrm{xx}^{*}$

\section{Introducción}

Hasta hace unas décadas la iushistoriografia argentina consideraba como límite de sus estudios, por lo menos para el derecho privado, el proceso histórico que finalizaba con la aparición de los códigos, consecuente con la centralidad que estos instrumentos jurídicos adquirieron en nuestra cultura jurídica. Todo el período posterior era considerado derecho vigente, y por lo tanto, ajeno a la mirada del iushistoriador.

Poco a poco esta situación se ha ido superando y el siglo XX, o por lo menos su primera mitad, se convirtió en un foco de atención para los historiadores del derecho. Se ha señalado que «entrar en el mundo de la Constitución y de los códigos implica avanzar resueltamente sobre el siglo $\mathrm{XX}$ » y que, en consecuencia, «la división de trabajo entre juristas positivos e iushistoriadores no pasa exclusivamente por fechas sino principalmente por percepciones e intereses intelectuales». ${ }^{1}$

Atender a la historicidad del derecho, incluso del vigente, implica reconocer que las expresiones jurídicas, a pesar del logicismo y tecnicismo que imperaron, y aún imperan, en el derecho contemporáneo no se reducen a estructuras dogmáticas o legales desconectadas de sus contextos sociales e ideológicos. Sostener lo contrario es reducir el derecho a «esquemas inútiles para la comprensión de la realidad», convirtiendo al método jurídico en «método de la indiferencia». ${ }^{2}$
Esta perspectiva cobra especial interés para aquellas investigaciones sobre derecho privado, y en especial el derecho de propiedad. Éste se manifiesta como "particularmente sensible a la mutación de las condiciones históricas», "expuesto a ver su propio esquema formal roto en diferentes puntos por la aparición de las exigencias que plantean los nuevos intereses». ${ }^{3}$ De ahí que la palabra propiedad, a pesar de su definición legal, «no tiene hoy un significado unívoco, si es que alguna vez lo ha tenido», y no puede mantenerse «la ilusión de que a la unidad del término corresponde la unidad real de una institución sólida y compacta». ${ }^{4}$

Creemos que los debates parlamentarios constituyen una fuente privilegiada donde es posible rescatar las múltiples significaciones de nuestras instituciones jurídicas y sus trasfondos ideológicos. En efecto, se ha visto en los parlamentos, una «asamblea de los representantes de los principales puntos de vista en conflicto en la sociedad», conduciendo sus «deliberaciones y toma de sus decisiones en el marco del conflicto y la controversia sobre los mismos» y creando derecho «sobre la base de las convicciones y los votos explícitamente partidistas de sus miembros». ${ }^{5}$ En este contexto, el derecho ya no sería una entidad abstracta y aséptica, lógica en sus consecuencias, sino más bien un tópico, ${ }^{6}$ la argumentación jurídica de un cierto posicionamiento ideológico, ${ }^{7}$ frente a las circunstancias fácticas de una determinada sociedad.

\footnotetext{
Proyecto Experiencias jurídicas en el derecho privado entre América Latina y Europa en la primera mitad del siglo XX (1901-1945), dirigido y financiado por el Max-Planck-Institut für europäische Rechtsgeschichte (Frankfurt am Main) y ejecutado en el Instituto de Investigaciones de Historia del Derecho (Buenos Aires). Agradezco las observaciones y comentarios que a mi trabajo hicieron Norberto Dagrossa, José Daniel Cesano, Eduardo Zimmermann y Alejandro Agüero.

1 TAu Anzoátegui (2010) 51.
}

2 Rodota (1986) 178-179.

3 Rodota (1986) 175-178.

4 Pugliatti (1954) 309, citado en Rodota (1986) 173. Grossi (1992) 19-23.

5 WALDRON (2005) 32-33.

6 Resulta siempre sugerente el análisis que Theodor Viehweg hace del derecho como tópico: puntos de vista directivos que retornan continuamente, temas fijos o, por decirlo así, clichés generalmente aplicables, cuya función consiste, fundamentalmente, en servir a una discusión de problemas, cuya naturaleza está, funda- mentalmente, en no perder nunca su carácter problemático. VIEHWEG (1986) 60-61.

7 En cuanto al término ideología, aclaramos que tomamos el mismo en un sentido lato, al que refiere Tarello, para indicar aquellas ideas de origen filosófico, teorías, argumentaciones doctrinales, en cuanto consideradas no tanto en sus fundamentos epistemológicos, sino en su función de constituir instrumentos de políticas socioculturales en general y de polí ticas jurídicas en especial. TARELLO (1988) 42. 
Hechas estas apreciaciones, este trabajo abordará el debate parlamentario de las leyes 11.152 y 11.157, que intentaron brindar una solución legislativa al problema habitacional que en ese momento atravesaba nuestro país. La hipótesis de nuestra investigación plantea que, lejos de buscar en las discusiones conceptos cerrados o rígidos, las referencias a nociones como código, derecho, propiedad, libertad de contratar, derecho extranjero nos remiten a lugares de discusión desde donde se argumentan las disímiles posturas suscitadas frente a las medidas proyectadas.

Una arista peculiar de nuestro análisis es el derecho extranjero como tópico. Nuestra mirada, más que simplificar, ${ }^{\mathbf{8}}$ intentará acercarse a la complejidad de los procesos de circulación de las ideas jurídicas y al seguimiento de los modelos jurídicos europeos que gravitaron sobre las élites argentinas durante la primera mitad del siglo XX.

En este sentido, se ha destacado el rol que jugaron las élites intelectuales. Académicos, expertos, políticos y juristas, receptivos a todo lo que proviniera del extranjero, fueron claves en estos procesos de transferencia de ideas, modelos, instituciones y fórmulas procedentes de distintos lugares, fundamentalmente de Europa y Estados Unidos, ${ }^{9}$ en un mundo que cada vez se encontraba más interconectado. Así, «la capacidad de persuasión de las nuevas ideas, su conexión con las existentes, la generación de otras, y los efectos de emulación, dependían, en todo caso, no sólo de cómo aquéllas habían llegado y de qué manera habían logrado moldearse en el nuevo entorno sino también de las posiciones de intermediación de los expertos con la política». ${ }^{\mathbf{1 0}}$
2 La cultura jurídica argentina de principios del siglo XX

La segunda mitad del siglo XIX, inaugurada con la constitución de 1853, implicó para la Argentina un profundo proceso de organización institucional y política, signado por el ideario modernizador que caracterizó a esta época y que también alcanzó al mundo jurídico. Al texto constitucional citado, integrado por la reforma constitucional de 1860, se agregarían los distintos códigos que se fueron sancionando a lo largo de este período, adquiriéndose de esta manera, de acuerdo con la mentalidad de nuestras élites, aquellos instrumentos normativos «modernos» que permitirían a nuestro país incluirse en el concierto de las naciones «civilizadas». ${ }^{11}$

El código introdujo en nuestra cultura jurídica un dispositivo innovador, ${ }^{\mathbf{1 2}}$ que si bien se nutría de modelos extranjeros, especialmente europeos, también apelaba a elementos tradicionales, conforme el eclecticismo reinante, ${ }^{\mathbf{1 3}}$ y cuya centralidad fue consolidándose hacia la séptima década del siglo XIX, gestando de este modo, especialmente en torno al código civil, lo que se ha dado en llamar la «cultura del código». ${ }^{\mathbf{1 4}}$

Estas afirmaciones no significan de ningún modo negar las resistencias contra el fenómeno codificador, coetáneas al mismo, y posteriormente, la posibilidad de su reforma. ${ }^{15} \mathrm{El}$ avance del tiempo, y sobre todo de las transformaciones económicas y sociales que caracterizarían el movimiento modernizador, dejarían al descubierto las brechas existentes entre las normas codificadas y la realidad en permanente cambio. En el umbral de la nueva centuria, Juan A. Bibiloni, quien luego fuera el redactor del Anteproyecto de Reforma del Código Civil, ${ }^{16}$ advertía:
8 Creemos que estas referencias al derecho extranjero no pueden, por lo menos en las fuentes que se analizan, ser reducidas a meros trasplantes legales mecánicos. WATsON (2000). Sobre la complejidad de estos procesos: Garcia Canclini (2010) 81-94. También encontramos un ejemplo en el trabajo de Cesano (2012).

9 García Sebastiani (2008) 354.

10 García Sebastiani (2008) 353.

11 Tau Anzoátegui (1977) 309ss.

12 Este aspecto innovador de los códigos no se contradice con la permanencia de elementos de una cultura jurídica tradicional que seguirá vigente a pesar de que ellos representaban, en muchos aspectos, un intento por reemplazarla. El alcance de esta interacción es objeto de variados estudios sobre la pervivencia del derecho indiano aun después de la sanción de los códigos.

13 TAu Anzoátegui (2000) 102-104.

14 Tau Anzoátegui (1998). Este autor acuñó para nuestro medio el tópico «cultura del código» como uno de los rasgos dominantes del derecho argentino en el siglo XX. Bajo esta de- nominación, cabe entender la concepción que hizo del código el objeto preferente, cuando no exclusivo, de estudio y que impuso un modelo de razonar ajustado a pautas estrechas. Ver también: LeIVA (1988) y TAu Anzoátegui (1982).

15 Tau Anzoátegui (1977) 365ss.

16 Dicho Anteproyecto fue el antecedente del Proyecto de Reforma al Código Civil de 1936. 
«... el siglo se va dejando una inmensa vacilación en el espíritu de los estudiosos. Las ideas experimentan una profunda transformación en materia de derecho privado, sin acertar a traducirse en formas definitivas ...» ${ }^{17}$

Esta necesidad de adaptación de las normas jurídicas al medio social estuvo íntimamente ligada, por lo menos en su fase teórica, con la irrupción de las ciencias sociales como movimiento crítico y reformador, que caracterizó, entre otras, la cultura jurídica argentina de principios del siglo XX. ${ }^{18} \mathrm{En}$ varias oportunidades se ha señalado la importancia que tuvieron las ciencias sociales en el mundo científico argentino de esta época ${ }^{19}$ y la forma en que sus razonamientos fueron incorporándose al bagaje intelectual de las élites. Las mismas apuntaban a enfrentar los nuevos problemas facilitando tanto «la acumulación de nuevos conocimientos 'científicos' sobre la sociedad, como la elaboración de un nuevo consenso ideológico que redefiniría las relaciones entre Estado y sociedad». ${ }^{20}$

Asimismo, ellas fueron la base de un «fluido movimiento de vinculación internacional entre los distintos grupos de 'expertos' que impulsaron un intenso tráfico transnacional de ideas, políticas e instrumentos legislativos, que resultaron imitados, copiados, transformados o adaptados a las realidades propias», desencadenándose «una tensión innegable entre las ambiciones universalistas propias del pensamiento científico y las demandas de los particularismos nacionales en los que las nuevas disciplinas se desarrollan». Según estos últimos, «los conflictos sociales internos y las propias tradiciones intelectuales determinaban la agenda de esas nuevas disciplinas». ${ }^{\mathbf{2 1}}$

En el ámbito del derecho, el embate sociológico se asoció a las críticas, que ya a fines del siglo XIX, ponían en duda el método exegético como único posible para la formulación del derecho. El poner en evidencia el «enorme abismo entre el fenómeno socio-jurídico y la ciencia del Derecho», dio pie al «surgimiento de una corriente de pensamiento que, antes que mirar la lógica formal de las normas, se dirigía principalmente a la realidad social que sustentaba las mismas». ${ }^{22}$ Para estos juristas, el derecho es la vida, que "como en la atmósfera, en él vivimos, nos movemos y existimos». ${ }^{23}$

Esta necesidad de adecuar el ordenamiento a las exigencias cambiantes de la sociedad argentina fue el reclamo de numerosas voces que, en ámbitos académicos y legislativos, insistían con la reforma de los códigos, en especial el civil. ${ }^{24}$

También instituciones reguladas en sus artículos pedían, a la luz de la realidad y de la legislación comparada, una revisión de sus principios. Una de ellas fue la propiedad, eje de la codificación decimonónica, a la cual se le achacaba, en distintos ámbitos, su extremado individualismo y la carencia de toda referencia, en su ejercicio, a las necesidades de la comunidad. ${ }^{25}$

3 El problema habitacional, el contrato de locación y la respuesta legislativa

Se ha señalado como una de las características del período en estudio, el proceso de urbanización de las principales ciudades argentinas, ${ }^{\mathbf{2 6}}$ que desencadenó no sólo un aumento del tamaño de éstas, sino una verdadera «revolución urbana», ${ }^{27}$ la que implicó, entre otras cuestiones, la transformación de varios de los viejos centros en ciudades modernas y la metropolización de Buenos Aires, Córdoba y Rosario. $^{28}$

En un corto lapso, la población de Buenos Aires aumentó de 187.000 habitantes en 1869 a 1.575 .800 en 1914; la de Córdoba de 29.000 a 122.000; y la de Rosario de 23.000 a $226.000 .^{29}$ Esta metamorfosis no sólo tuvo implicancias de índole técnica, en cuanto a los métodos y la organización de la industria de la construcción, sino que también se proyectó en las esferas sociales, económicas y políticas de nuestro país. Una de las
17 Bibiloni (1911).

18 Tau Anzoátegui (2007a).

19 Altamirano (2004); Botana/Gallo (2007) 89-101 y 138-148; SERRAFERO (2003); Barbé/Olivieri (1992).

20 Altamirano (2004) 37; Zimmermann (1995) 83-100.

21 ZimMERMANN (2008) 174-175.

22 Tau Anzoátegui (2007a) 19-23; Hespanha (2002); Polotto (2006).
23 Dellepiane (1908) 369.

24 Díaz Couselo, José María (2007). Ver especialmente los textos allí recopilados.

25 Levaggi (2007). Ver Martinez Paz (1916) 249-257.

26 LeCuONa (1993); LeIERNuR (2000).

27 Leiernur (2000) 411. Este mismo autor da cuenta de las siguientes cifras que revelan el crecimiento de las ciudades argentinas en este período: en 1869 sólo el $28,6 \%$ del total de 1.737.000 argentinos vivía en ciudades; cuarenta y cinco años más tarde éstos pasan a constituir el $52,7 \%$ de los 7.885.200 habitantes.

28 LEIERNUR (2000) 411.

29 LEIERNUR (2000) 412. 
cuestiones que preocupó a las élites gobernantes e intelectuales del período, con distinta intensidad y resultado, fueron las dificultades habitacionales de las clases menos favorecidas.

Es verdad que los reclamos sociales referidos a esta cuestión, esto es, entre otros, la escasez de viviendas, el hacinamiento de las familias en los conventillos, ${ }^{30}$ sus condiciones de higiene, el precio elevado de los alquileres, no encontraban su causa sólo en las políticas habitacionales, sino que se enmarcaban en un contexto más amplio signado por las transformaciones y crisis económicas que afectaron a nuestro país en el proceso de entreguerras. Las nuevas problemáticas pusieron en juego la democratización del sistema político que abrió la reforma electoral de 1912, aguzando «la sensibilidad de los legisladores frente a las demandas más urgentes de sus votantes». ${ }^{31}$

La situación en que se encontraban las clases obreras y marginales de la población era objeto de estudios e investigaciones, que intentaban, mediante un análisis de la realidad, definir políticas concretas para paliar las diversas problemáticas. ${ }^{32}$ Ejemplo de ello es el Primer Congreso de la Habitación organizado por el Museo Social en septiembre de 1920, donde se discute ampliamente la situación.

La creación de la Cooperativa El Hogar Obrero en 1905 y la sanción en 1915 de la ley 9.677 que creaba la Comisión Nacional de Casas Baratas fueron algunas de las iniciativas surgidas desde distintos sectores que pretendieron dar una respuesta al problema habitacional. ${ }^{33}$

Si bien parecidas circunstancias habían rodeado la llamada «huelga de inquilinos» de $1907,{ }^{34}$ a fines de la década del '10 la falta de viviendas, originada principalmente por la paralización de la construcción y el crecimiento de la población, produjeron un aumento en los precios de los alquileres, en algunos casos del 50\% respecto de los que se cobraban en 1918, lo que representaba casi la totalidad del salario del trabajador. ${ }^{35}$

La situación descripta originó diversas propuestas en el Congreso de la Nación. En el transcurso de 1919, se presentaron varios proyectos que planteaban como solución desde la limitación del precio de los alquileres ${ }^{36}$ y la suspensión de los juicios de desalojo por un tiempo determinado, ${ }^{37}$ hasta la creación de comisiones arbitrales. ${ }^{38} \mathrm{Si}$ bien estas medidas se concebían como leyes de emergencia con el fin de paliar una situación que, si bien dramática, era considerada excepcional, algunos legisladores reclamaban también, una reforma general del régimen de locaciones, tanto urbanas como rurales. $^{39}$

Los proyectos así ingresados fueron objeto del estudio de la comisión de legislación de la Cámara, integrada en ese entonces por los diputados Anto-
30 Los conventillos constituían una sucesión simple de cuartos iguales entre sí, alineados a lo largo de uno o ambos lados de un espacio abierto de menor dimensión eufemísticamente llamado patio, al final del cual se agregaba un número generalmente exiguo de retretes y piletones ... En Buenos Aires había 1770 de estas viviendas/casas de vecindad al comenzar la década de 1880. En ellas 51.915 personas habitaban 24.023 habitaciones. Diez años más tarde, 93.743 habitaban 37.603 habitaciones. La cantidad de personas por habitación creció de 2,16 a 2,49. En 1913 el índice de ocupación era mayor aún: 3,7 personas por habitación. Todavía en 1917 el 88,4\% de las familias obreras vivía en una única pieza, LeIERNur (2000) 433-434.

31 Halperín Donghi (1999) 188.

32 Leiernur (2000) 436 ss.

33 LeIERNUR (2000) 436 ss.

34 Suriano (1983).
35 Esta situación es ampliamente descripta en los debates, con estadísticas y estudios.

36 En este sentido, el proyecto de Rodolfo Moreno (h) y Pedro P. Pages, de fecha 11 de junio de 1919, que limitaba el precio del alquiler al 7\% del valor fijado para el pago del impuesto de contribución territorial; el de José P. Tamborini, presentado el 17 de mayo de 1920, que lo limitaba al 8\%,y establecía que en el caso de las casas de vecindad el precio de la locación sería fijado anualmente por el Departamento Nacional del Trabajo; el de Andrés Ferreyra (hijo), de fecha 17 de mayo de 1920, que lo limitaba en general al $9 \%$ sobre dicho impuesto y distinguía otros supuestos donde fijaba un valor distinto. En la sesión del 16 de junio del mismo año, el diputado Ricardo Pereyra Rosas presentaba un proyecto que limitaba el alquiler al precio percibido en mayo de 1920, Sesión del 11 de junio de
1919, Congreso nacional (1919 I) 487; Sesión del 16 y 17 de mayo de 1920, Congreso NACIONAL (1920 I) 215 y $255,751$.

37 Es el caso del proyecto presentado por Delfor del Valle en la sesión ordinaria del 17 de mayo de 1920, Congreso NACIONAL (1920 I) 277.

38 Proyecto de Víctor M. Molina, presentado en la sesión ordinaria del 19 de mayo de 1920. Estas comisiones resolverían en forma breve y sumaria los reclamos que interpusieran los inquilinos, en los casos que no hubiese contrato por escrito, sobre aumento y fijación de alquileres, Sesión del 19 de mayo de 1920, Congreso NACIONAL (1920 I) 300-319.

39 Sesión ordinaria del 16 de junio de 1920, Congreso NACIONAL (1920 III) 771; Sesión del 5 de Agosto de 1920, Congreso nacional (1920 III) 854-855. 
nio de Tomaso, José León Rodeyro, Arturo M. Bas, Manuel Mora y Araujo, Julián Maidana y Nicolás A. Avellaneda. En la sesión ordinaria del 29 de julio de 1920, evidenciando las profundas divergencias que el tema producía entre sus miembros, ${ }^{40}$ la comisión presentó a la cámara dos despachos diferentes. ${ }^{\mathbf{4 1}}$

El primero de ellos fue suscripto por los diputados Mora y Araujo, Roydero y de Tomaso, y en disidencia por el diputado Maidana, y contenía dos proyectos que separaban la reforma de la ley de fondo, ${ }^{42}$ de aquellas medidas que, consideradas de carácter "ocasional y transitorio» intentaban solucionar el encarecimiento de la vivienda. ${ }^{43} \mathrm{El}$ segundo fue firmado por el diputado Bas y, en disidencia, por Avellaneda. Ambos despachos introducían modificaciones al título sobre la locación en el código civil. ${ }^{\mathbf{4 4}}$ Éstas giraban principalmente en torno a la determinación de un plazo legal para aquellos arrendamientos donde no hubiese contrato por escrito. ${ }^{45}$ También se preveía, en el despacho mayoritario, medidas procesales tendientes a mejorar la situación de los locatarios y sublocatarios ante el desalojo, mientras que en el proyecto del diputado Bas se ponía el acento en la promoción de la edificación, a través de la adjudicación de mayores fondos a la Comisión de Casas Baratas y un régimen de exenciones impositivas.

Otro punto importante era aquél referente al precio de la locación. Mientras que el primer despacho declaraba sin efecto los aumentos en el precio de los arriendos desde el $1^{\circ}$ de enero de 1920, la propuesta de Bas disponía el arbitraje como solución.

La disidencia del diputado Avellaneda al proyecto de Bas se enfocaba, como la del diputado Maidana, en considerar que la solución al proble- ma consistía en el fortalecimiento de la oferta y demanda habitacional mediante la promoción de la construcción. Este argumento se convirtió en un verdadero alegato contra los proyectos que contrariaban, quebraban y destruían «principios básicos de nuestra legislación de fondo»: ${ }^{46}$

«... no es seguramente con reformas violentas de nuestra legislación fundamental, ni con ataques inmotivados a los derechos más legítimos que adornan la personalidad humana, con lo que vamos a impulsar e intensificar la edificación de las viviendas, única forma de salvar la difícil situación de los que nunca pudieron ahorrar para levantar su propia morada y a la que tienen legítimo derecho de aspirar los hijos del infortunio». ${ }^{47}$

Su reacción se materializaba con la presentación de otro proyecto de ley que aseguraba una solución conservadora al problema: la suspensión de las sentencias de desalojo, la instrumentación de una serie de medidas impositivas a fin de facilitar la construcción y la provisión de mayores fondos a la Comisión de Casas Baratas. ${ }^{48}$

La complejidad de las posiciones enfrentadas en las discusiones obligó a que en la sesión ordinaria del 4 de agosto la Cámara de Diputados se constituyera en comisión a fin de considerar los proyectos presentados sobre contratos de locación de inmuebles. ${ }^{49}$

En la sesión del 19 de agosto, cuyo debate duró hasta altas horas de la madrugada, la votación de los proyectos se efectuó en base a cuatro anteproyectos que recogían las discusiones hasta ese momento mantenidas: el primero introducía modificaciones al código civil en materia de locaciones; el segundo
40 A esta situación alude el miembro informante de la comisión, diputado Manuel Mora y Araujo: «La comisión no pudo informar su opinión como fuera su anhelo y su propósito, porque entre la mayoría que subscribe un despacho y el señor diputado doctor Bas no fué posible armonizar los puntos de vista en que ambas partes se colocaban.» Sesión del 29 de julio de 1920, Congreso Nacional (1920 III) 676-677.

41 Congreso nacional (1920 III) 668 ss.

42 Así lo señalaba el diputado de Tomaso en el debate: «la comisión ... pensó, sin embargo, que valía la pena, ya que nos ocupábamos de la cuestión a raíz de una situación actual, de una situación que ha parecido desesperante, que aprovecháramos la oportunidad para incorporar algunos cambios de detalle en el código civil, dándole a la reforma un carácter más estable, en el sentido de proteger para siempre los legítimos derechos de los inquilinos». Congreso nacional (1920 III) 736.

43 Congreso nacional (1920 III) 676.

44 Se proponía la modificación de los artículos 1507, 1509, 1583, 1604 y 1610 (vieja numeración) del código civil (el despacho del diputado Bas refería a los artículos 1541, 1543, 1617, 1638 y 1644 - numeración nueva).

45 En el despacho mayoritario se disponía dos años, mientras que en el proyecto del diputado Bas el plazo era de un año.

46 Congreso nacional (1920 III) 721.

47 Congreso nacional (1920 III) 724.

48 Congreso nacional (1920 III) 724.

49 Congreso nacional (1920 III) 802 ss. 
proponía una serie de medidas procesales referidas a este contrato; el tercero se refería en concreto a las medidas de emergencia, como la determinación legal del precio de la locación y suspensión de los desalojos, y el cuarto contenía medidas fiscales. En esa oportunidad, se sancionó este último y sólo los tres primeros se modificaron. ${ }^{50}$

Remitidos al Senado, el despacho de la comisión de códigos de esa Cámara propuso la sanción de los proyectos, aunque el senador Pedro A. Garro firmó en disidencia en razón de que los proyectos implicaban una reforma del código civil. ${ }^{51}$ Éstos fueron informados por el senador del Valle Iberlucea, en la sesión ordinaria del 21 de abril de 1921. La réplica conservadora estuvo en manos del senador Leopoldo Melo, que presentó dos proyectos de ley que variaban sustancialmente las disposiciones sancionadas en la Cámara de Diputados. El primer proyecto, además de prever medidas tendientes a garantizar los derechos de los sublocatarios y la publicidad del precio del alquiler, establecía como «especulación ilícita» todo «acto, combinación o acuerdo para determinar o producir el alza del precio de los alquileres sobre el monto correspondiente al establecido por la concurrencia natural y libre de la oferta y la demanda, y los aumentos derivados de los impuestos y cargas que graviten sobre los inmuebles». ${ }^{52}$ El segundo proyecto limitaba sustancialmente la prórroga del precio de los alquileres al establecer que «todos los contratos de locación o sublocación, escritos o verbales, sobre fincas destinadas a habitaciones, en los que el alquiler no exceda de pesos trescientos moneda nacional mensuales, cuyo término esté por vencer o haya vencido, pero a pesar del vencimiento, el locatario continúe ocupando el local, quedarán prorrogados hasta el 31 de julio de 1922». ${ }^{53}$
Con este panorama, el Senado, desechó los proyectos sancionados en la Cámara de Diputados $\mathrm{y}$, con modificaciones, sancionó los proyectos presentados por el senador Melo en su sesión del 23 de abril de 1921. ${ }^{54}$

Vuelta la cuestión a la Cámara de Diputados, la situación planteada por el Senado obligó a aquélla a expedirse, en su sesión ordinaria del 9 de junio de 1921, preservando su carácter de cámara iniciadora en los proyectos tramitados a fin de no perder los privilegios que en este sentido le confería la Constitución Nacional. ${ }^{55}$ Así, rechazó las modificaciones planteadas por la otra cámara, insistiendo en la sanción de los proyectos propuestos oportunamente por ella. El Senado aceptó la insistencia de la Cámara de Diputado y sancionó los proyectos en su sesión del 15 de septiembre, ${ }^{56}$ convirtiéndose los mismos en las leyes 11.156, que introducía modificaciones al código civil en materia de locaciones urbanas, y 11.157, que decidió la prórroga del precio de los alquileres.

$4 \quad$ El análisis del debate: consideraciones en cuanto a los tópicos jurídicos y trasfondos ideológicos

La tramitación de la ley produjo un riquísimo debate propio de este tipo de discusiones. La variedad de los temas tratados tuvo relación directa con la complejidad que presentaba el tema de la vivienda, su incidencia social y económica, las políticas habitacionales e impositivas y por supuesto sus aspectos jurídicos. ${ }^{57}$ Con respecto a estos últimos, nuestro análisis se ha centrado en los siguientes tópicos que aparecen en los discursos: el código civil como expresión de los «principios
50 Sesión del 19 de agosto de 1920 , Congreso nacional (1920 IV), 267-395.

51 Sesión del 21 de abril de 1921 , Congreso nacional Senadores (1921 II) 65 .

52 Congreso nacional Senadores (1920 II) 84 .

53 Congreso nacional Senadores (1920 II) 84 .

54 Sesión extraordinaria del 23 de abril de 1921, Congreso nacional Senadores (1920 II) 87.

55 El despacho, firmado con fecha 2 de junio de 1921, fue presentado por las comisiones de legislación general y negocios constitucionales de la Cámara y suscripto por los diputados Manuel Mora y Araujo, Valentín Vergara, Arturo M. Bas, Mario Bravo, Pedro F. Gibert, Arturo Isnardi, José L. Rodeyro y Antonio de Tomaso. Sesión del 9 de junio de 1921, Congreso nacional (1921 I) 472.

56 Sesión del 15 de septiembre de 1921, Congreso nacional (1921 I) 438 ss.

57 Resulta interesante señalar aquí algunas de las temáticas que se debatieron en ambas cámaras y que por el objeto de este estudio no serán abordadas, pero que revelan la riqueza de las discusiones: el crecimiento demográfico y su impacto social y económico, la situación de las clases trabajadoras, las condiciones habitacionales de éstas, la relación entre vivienda e higiene, la determinación de la contribución territorial, el abuso de los intermediarios o trust, la política impositiva con relación a la construcción de viviendas, etc. 
jurídicos fundamentales»; el derecho como realidad social y dinámica que superaba los esquemas de un código; la crítica de un derecho de propiedad absoluto; la función social de la propiedad; la crítica del principio de libertad de contratar fundado en una igualdad «ficticia»; la validez de las leyes de emergencia; la referencia al derecho extranjero como legitimador de las propuestas reformistas.

Ahora bien, y para ser consecuentes con el objetivo planteado en la introducción de nuestro trabajo, nos interesa vislumbrar cuál era la particular postura ideológica, más allá de la partidaria esgrimida por cada uno de los legisladores, subyacente en las construcciones jurídicas articuladas en el debate. Y sin ánimo de simplificar la cuestión, podríamos afirmar que los distintos tópicos enunciados se dirigen a legitimar un determinado rol que el Estado debía jugar frente a las cuestiones sociales planteadas: si debía mantenerse al margen, defendiendo «el poder absoluto» del propietario; o, por el contrario, intervenir, regulando esa esfera privada que el derecho liberal consideraba ajena a la jurisdicción estatal.

Se ha señalado que el fenómeno estatal se construyó en base a una retirada del poder doméstico, sustraído éste del universo público de la ley y la justicia, que transfirió sus poderes al sector público. ${ }^{58} \mathrm{El}$ orden político-jurídico decimonónico se erigiría sobre un nuevo poder, el propietario, constituido como un derecho «contra» el Estado, esto es, una esfera de libertad «que ni los otros ciudadanos ni los organismos estatales pueden rozar». ${ }^{59}$ En este sentido, el propio código civil, expresión de ese orden estatal, se «pone a sí mismo, como ley al servicio de este derecho, el derecho de propiedad», y que al caracterizarlo como absoluto "genera dimensión propia de dominio». ${ }^{\mathbf{6 0}}$
Sin embargo, existen testimonios de la época que dan cuenta que, más allá del discurso liberal preconizado en constituciones y códigos, persistía en el orden político argentino una estructura doméstica de origen tradicional, legitimada por este derecho de propiedad. ${ }^{61}$ Quizás el poder de este orden propietario podía advertirse con mayor nitidez en los pormenores del arrendamiento rural, como algunos legisladores señalaban:

«... este debate servirá [...] también para los arrendatarios del campo que están sufriendo las consecuencias extraordinarias de un régimen de feudalismo que en la interpretación de determinados tribunales ha llegado hasta falsear los preceptos amplios del codificador - me refiero, por ejemplo, al contrato de aparcería» ${ }^{62}$ [...] «Nuestros grandes propietarios rurales suelen considerar que el campo pelado es lo único a que tienen derecho, lo único que pueden reclamar los arrendatarios, porque para el gran propietario argentino el concepto social de la necesidad humana de la vivienda todavía no existe. Cree que a los seres humanos, a los cuales entrega su campo para ararlas, para mejorar los pastos, para ponerlo en mejores condiciones de explotación ganadera debe entregárseles pelado para que acampen en él, por años, familias enteras, y del cual deberán desaparecer cuando al propietario se le ocurra entregar ese campo a otro destino. $Y$ es ese un concepto social profundamente arraigado en nuestras grandes clases sociales, en esas que podríamos llamar gobernantes, de donde salen, casi siempre, los presidentes argentinos, porque todavía no se ha visto en nuestro país un sólo presidente quo baya sido industrial, que haya salido de una fábrica, pues todos han sido invariablemente estancieros y terratenientes». ${ }^{63}$
58 Clavero (2007) 254-257 y 141-147.

59 Costa (2004) 59.

60 Clavero (1998) 311; Grossi (1992) 107-116, 123-133; TARELLO (1988) 55-57.

61 Así lo advertía José Nicolás Matienzo: «Las dos cámaras del Congreso [...] están compuestas de ciudadanos de la misma clase social, de lo que pudiera llamarse la clase gobernante del país. Porque, aunque la revolución de la independencia proclamó la igualdad ante la ley y este principio ha sido reiterado por todas las constituciones argentinas, nacionales y provinciales, él no ha podido en la práctica cambiar fundamentalmente la contextura de la sociedad colonial, a pesar del ingreso de los mercaderes, artesanos y proletarios a la vida pública. Las familias que formaban la capa superior de la población de las provincias de la real Audiencia de Buenos Aires, aquellas cuyos jefes se denominaban la parte más sana del vecindario y tenían el privilegio de ser invitables a los cabildos abiertos, siguen constituyendo por medio de sus descendientes el núcleo social, algo engrosado por la incorporación de elementos advenedizos a quienes la fortuna le ha sonreído y ayudado» (el subrayado es nuestro), Matienzo (1917) 175-176. Ver Botana (1998) 65-81.

62 Discurso del diputado Leónidas Anastasi (el subrayado es nuestro), Congreso nacional (1920 III) 771.

63 Discurso del diputado Nicolás Repetto (el subrayado es nuestro), Congreso nacional (1920 III) 854-855. 
Las nuevas problemáticas que surgían de la inmigración, la modernización y el proceso democrático, replantearían este orden de poderes a favor del Estado, al cual se le reclamaba un papel más activo «en la conformación de una agenda pública sobre economía, los problemas sociales y la reforma política-institucional». ${ }^{64}$ Desde los viejos moldes del derecho liberal se intenta legitimar este nuevo rol:

«El Estado no importa una forma «estática〉 [...]. Y por ello en cada país y en cada momento histórico, se entiende de manera diversa como ha de asegurarse la libertad. Quizás ha pasado ya la era del individualismo liberal [...]. Y toda la legislación stuitiva) de los estados modernos, importa una rectificación categórica del liberalismo revolucionario que pareció durante un siglo ser la última palabra que había de pronunciar la libertad sobre la tierra». ${ }^{65}$

En este contexto, el código civil aparece insuficiente como instrumento regulador:

«Cuando Vélez proyectó su código, no hay duda de que las relaciones entre inquilinos y propietarios en la República Argentina, y sobre todo en la ciudad de Buenos Aires, estaban colocadas en otro pie que en la actualidad. Buenos Aires era entonces una gran aldea y las relaciones entre propietarios e inquilinos tenían un carácter que me atrevería a llamar familiar. ${ }^{66}$ Las cosas han cambiado desde entonces en virtud del progresivo crecimiento de esta ciudad, que ha llegado a convertirse en una de las más grandes del mundo [...]. Las relaciones, pues, entre propietarios e inquilinos, en virtud de esas razones de orden económico, social y hasta físico, diría, se han transformado en el hecho, y es indispensable que la ley se adapte a esa realidad». ${ }^{\mathbf{6 7}}$
Podemos apreciar que las discusiones no se sustentaban tanto en una descripción técnica del derecho de propiedad, sino en las implicancias políticas de este derecho como esfera de poder: expresado como absoluto e inmutable aparecía como valla a la intervención estatal reclamada por algunos sectores; por el contrario, su flexibilidad, la posibilidad de limitación, constituía una forma de legitimarla.

Este dilema se proyectaría en el fallo «Ercolano c. Lanteri de Renshaw», del 28 de abril de 1922, en el que la Corte Suprema de la Nación resuelve la constitucionalidad del artículo $1^{\circ}$ de la ley 11.157 , que establecía la prórroga del precio de los alquileres vigente al $1^{\circ}$ de enero de 1920 :

«Ni el derecho de usar y disponer de la propiedad, ni ningún otro derecho reconocido por la Constitución, reviste el carácter de absoluto. Un derecho ilimitado sería una concepción antisocial. La reglamentación o limitación del ejercicio de los derechos individuales es una necesidad derivada de la convivencia social [...] circunstancias muy especiales en que por la dedicación de la propiedad privada a objetos de intenso interés público y por las condiciones en que ella es explotada, justifican y hacen necesaria la intervención del estado en los precios, en protección de intereses vitales de la comunidad [...]. La reglamentación del precio del alquiler no se propone favorecer a unos con perjuicio de otros. Su finalidad es impedir que el uso legítimo de la propiedad se convierta en un abuso perjudicial en alto grado, merced a circunstancias que transitoriamente han suprimido de hecho la libertad de contratar para una de las partes contratantes». ${ }^{68}$
64 Zimmermann (2008) 183; Halperín DonghI (1999) 183-196; SEgOVIA (2007).

65 Vedia y Mitre (2007) 408.

66 La cursiva es nuestra.

67 Del discurso de Tomaso, Congreso NACIONAL (1920 III) 738. En el mismo sentido lo sostenía el senador del Valle Iberlucea: «No hay duda que nuestro Código Civil pudo legislar sabiamente la locación de cosas para la sociedad argentina de hace medio siglo, que era una sociedad casi rudimentaria, de una estructura simple, sencillísima, medio colonial todavía; pero así como hubo necesidad, andando el tiempo, de dictar leyes sobre el trabajo, en virtud de las exigencias de la industria, porque eran insuficientes las disposiciones del Código Civil sobre la locación de servicios, así también hay necesidad en estos momentos históricos de sancionar nuevas disposiciones que modifiquen los preceptos contenidos en el mismo código en lo relativo a la locación de cosas. por exigencia de las actuales condiciones sociales y de acuerdo con las modernas ideas del derecho a la habitación». Congreso nacional Senadores (1920 II) 72.

68 Fallos de la Corte Suprema de Justica de la Nación, Tomo 136, 170. 
5 El código civil como expresión de los «principios jurídicos fundamentales»

En torno a la idea de código y su posible reforma se desarrolló uno de los puntos álgidos de la discusión. El código como expresión de los principios jurídicos fundamentales e inmutables ${ }^{\mathbf{6 9}}$ de la República $^{70}$ era el núcleo central de aquellos ${ }^{71}$ que entendían «inadmisibles e inconducentes» ${ }^{72}$ las reformas propuestas. ${ }^{73}$

Como recurso retórico, se apelaba al recitado de los numerosos artículos del código civil referidos a la cuestión, como si con ello bastara para evidenciar un orden elocuente en sí mismo, ${ }^{74}$ actitud acompañada de cierto sentido reverente al codificador y su obra. ${ }^{75}$

Las consecuencias de la alteración de estos principios eran descriptas en términos catastróficos: ${ }^{76}$ implicarían la legitimación de la arbitrariedad, ${ }^{77}$ la desorientación, ${ }^{78}$ la desnaturalización del contrato de locación y la destrucción del principio de libertad de contratar, ${ }^{79}$ la desaparición de la estabilidad de todos los derechos, el reemplazo por el caos del orden social y jurídico existente, ${ }^{\mathbf{8 0}}$ además de ser «repugnantes» a la constitución y al código civil. ${ }^{\mathbf{8 1}}$

La imposibilidad de aplicar retroactivamente las medidas tachaban de inconstitucionales los proyectos debatidos, en tanto que amenazaban un orden descripto en el código civil que se identificaba con el protegido por nuestra ley fundamental. Del otro lado se denunciaba el recurso de inconstitucionalidad como el «más a mano cuando se trata de poner barreras a la reforma de los viejos moldes donde arraigan los intereses creados». ${ }^{\mathbf{8 2}}$

La solución no se encontraba «haciendo pedazos» el «orden jurídico fundamental», ${ }^{\mathbf{8 3}}$ «contrariando, quebrantado y destruyendo principios básicos de nuestra legislación de fondo», ${ }^{\mathbf{8 4}} \mathrm{ni}$ en «reformas violentas», ni en "ataques inmotivados a los derechos más legítimos que adornan la personalidad humana», ${ }^{\mathbf{8 5}}$ sino que, al ser el problema
69 Congreso nacional (1920 III) 721.

$70 \ll$... porque creo que no puede haber república ni orden social, ni hogar, ni patria sin las leyes fundamentales que nos rigen", del discurso del diputado Maidana, Congreso NACIONAL (1920 III) 871 .

71 Postura sostenida en diputados, principalmente por Marcelo G. Sanchez Sorondo y Julián Maidana, mientras que en Senadores por Pedro A. Garro y Leopoldo Melo.

72 Del discurso del diputado Maidana, Congreso nacional (1920 III) 721,

73 Desde esta postura, «la defensa intransigente de la libertad y de la propiedad, y el consecuente juego de la demanda y la oferta, son capaces de multiplicar la riqueza colectiva y de incrementar la civilización, y bastan por tanto para resolver a largo plazo el problema de la pobreza y de los conflictos alimentados por ella [...] no pueden admitirse pretensiones jurídicamente eficaces frente al Estado para obtener su intervención spositiva»", Costa (2004) 59.

74 Congreso nacional (1920 III) 721.

75 «... no puedo tolerar que un diputado, como lo hace el señor diputado de Tomaso y como lo hace el señor diputado Dickmann, trate despectivamente la obra monumental del doctor Vélez Sársfield, refiriéndose a él hasta con cierta familiaridad que yo no les tolero ni les permito. Lo llaman Vélez. ¡El insigne Vélez!, debían decir, señores diputados», Discurso del diputado Maidana, Congreso NACIONAL (1920 III) 871-872.

76 Esta visión catastrófica de las reformas es advertida por el diputado socialista de Tomaso: «La corporación de propietarios inició un gran debate alrededor de estas ideas por medio de los diarios; envió a la cámara folletos y peticiones de todo género y sacó a relucir, como era de esperar, todos los artículos de la constitución y del código civil, aun cuando no tengan ninguna atinencia con el asunto, tratando de presentar las ideas emitidas en el seno de la comisión como ideas inspiradas en el propósito de cambiar catastróficamente el orden social de la república». CoNGreso NACIONAL (1920 III) 726.

77 Así lo sostenía el diputado Sanchez Sorondo: «Creo, señor presidente, que estamos tomando un camino peligroso. Las construcciones jurídicas no se modifican a mérito de razones sentimentales ... si salimos del camino trazado por la ciencia jurídica en esta materia y legislamos, bajo el apremio de circunstancias y por razones muy loables, pero que no tienen nada que hacer con la garantía de los derechos, nos exponemos a caer en plena arbitrariedad». Congreso NACIONAL (1920 III) 767.

78 Del discurso del diputado Ferreyra: «No podemos encarar este asunto de otra manera, porque sabemos que estos proyectos modifican principios que muchos han aprendido a considerar como inmutables; $y$, por consiguiente, si nos encontramos de pronto con una serie de proyectos que modifican tales principios, la desorientación es explicable y prolongar, sin fijar un criterio, esta discusión es prolongarla sin resultado práctico alguno». Sesión del 4 de agosto de 1920 , Congreso nacional (1920 III) 797.

79 Del discurso del diputado Maidana, Congreso nacional (1920 III) 721.

80 Del discurso del diputado Maidana, Congreso nacional (1920 III) 724.

81 Del discurso del diputado Maidana, Congreso nacional (1920 III) 721.

82 Del discurso del diputado informante Mora y Araujo, Congreso NACIONAL (1920 III) 678.

83 Del discurso del diputado Maidana, Congreso nacional (1920 III) 788.

84 Del discurso del diputado Maidana, Congreso nacional (1920 III) 721.

85 Del discurso del diputado Maidana, Congreso nacional (1920 III) 724. 
económico, se debía profundizar una receta tradicional: lograr recomponer el equilibrio entre la oferta y la demanda: ${ }^{86}$

«No con reformas del código civil sino removiendo los inconvenientes que hay para que se construyan casas baratas; y no se estimula absolutamente la construcción de casas baratas poniendo cerrojos a la iniciativa y al movimiento libre del capital». ${ }^{87}$

En todo caso, cualquier reforma debía ser no una imposición de las «leyes de la demagogia» o fruto de «innovaciones arriesgadas», ${ }^{\mathbf{8 8}}$ introduciendo «en el código principios que no son sino un reflejo del momento actual»; ${ }^{89}$ la modernización de los «viejos códigos» debía surgir no «sobre el tambor batiente», sino de «la mayor meditación» 90 y de la «serenidad del espíritu»: ${ }^{\mathbf{9 1}}$

«... pero esas reformas han de ser prudentes, meditadas y serenas; han de hacerse, deben hacerse, con el aporte de las universidades, de los jurisconsultos, de los maestros en derecho, de la jurisprudencia y de todas las actividades de la vida nacional, impidiendo así los erectos de los impromptus, de los apresuramientos, de la influencia de las impresiones de acontecimientos transitorios, influencia que conduce a querer incorporarlas a los códigos de fondo, para modelar la nación a imagen y semejanza de esas impresiones, cuando no a imagen y semejanza de lo que se hace en otros países, como si los argentinos, como todos los pueblos, no tuviéra- mos nuestras costumbres, nuestros sentimientos y nuestras ideas y todo tuviéramos que pedirlo prestado al extranjero, hasta las leyes, que es lo más nacional que puede haber en un pueblo». ${ }^{92}$

6 El derecho como realidad social y dinámica que superaba los esquemas del código

Frente a éstas se impusieron aquellas argumentaciones que entendían que las modificaciones no implicaban «perturbar el juego armónico de las relaciones de derecho creadas y tuteladas por la ley», "apartarse de los principios básicos del codificador, pero sí adaptándolos con más amplitud y elasticidad de criterio a las nuevas y más complejas modalidades de la vida moderna». ${ }^{93}$

Identificaban el derecho como un producto de la realidad social y económica de un pueblo, donde las normas no debían quedarse estancadas en esquemas arcaicos, sino ser sometidas a un permanente cotejo con dicha realidad, reformándolas para adaptarlas a las situaciones que debían regir. Expresadas en términos evolutivos, y sometidas al paradigma de la modernización, existían fórmulas jurídicas que resultaban más avanzadas, esto es más adaptadas a las transformaciones producidas, identificándose en general con aquellas, como luego se verá, provenientes del derecho extranjero, especialmente el europeo.

El diputado Manuel Mora y Araujo, como miembro informante de la comisión de legislación de la Cámara de Diputados, afirmaba al presentar el despacho de la mayoría:
86 En este sentido se expide el diputado Maidana: «De lo que dejo expuesto, señor presidente, lógica y racionalmente se deduce que el procedimiento a seguir para llegar al abaratamiento del alquiler es impulsar e intensificar la edificación hasta llegar a equilibrar la oferta con la demanda, que es, indiscutiblemente, la ley económica universal que determina el precio de las cosas», Congreso nacional (1920 III) 720.

En el mismo sentido, el diputado Sanchez Sorondo: Congreso NACIONAL (1920 III) 768; diputado del Valle: CONGRESO NACIONAL (1920 III) 781. También el senador Garro: Congreso nacional Senadores (1920 II) 79. También el senador Melo:
Congreso nacional Senadores (1920 II) 82 .

87 Del discurso del diputado del Valle, Congreso nacional (1920 III) 781.

88 Del discurso del diputado Avellaneda, Congreso nacional (1920 III) 671.

89 Del discurso del diputado Quirós, Congreso nacional (1920 IV) 338.

90 Del discurso del diputado Thierney, Congreso nacional (1920 IV) 345.

91 Del discurso del diputado Martinez, Congreso NACIONAL (1920 III) 742-743.

92 Del discurso del diputado Quirós, Congreso nacional (1920 IV) 338. En el mismo sentido, el senador Garro: Congreso NACIONAL Senadores (1920 II) 79.
93 Mora y Araujo entiende que dentro de los principios básicos de la codificación argentina está la estabilidad del contrato de locación. Las reformas proyectadas acogerían y profundizarían ese principio extendiéndolo a las locaciones contratadas en forma verbal. De esta manera, la reforma corregiría las derivaciones contrarias al principio vital del contrato mismo, que radica en el consentimiento de las partes, y sugiere prevenciones legítimas sobre los abusos y las injusticias a que podría dar lugar en detrimento del orden social. CONGRESO NACIONAL (1920 III) 676-677. 
«Dentro de un estado social en el cual el régimen de la propiedad inmueble ha evolucionado en los pueblos de más alta civilización de acuerdo con los intereses de orden económico, no habría por qué mantener dentro de fórmulas tradicionales, muy respetables pero ya inconducentes, el contrato de locación y sublocación, que son las dos formas más generales y útiles en que la propiedad inmueble concurre al desarrollo y progreso de los pueblos». ${ }^{94}$

Justificaba la reforma del código civil en razón de que muchas de las disposiciones proyectadas afectaban "artículos vigentes del código civil, dentro de cuyas fórmulas rígidas y estrictas era muy difícil, si no imposible, encuadrar disposiciones de una ley ocasional y transitoria».

Estos «reformistas», ${ }^{95}$ como despectivamente eran considerados por algunos legisladores, denunciaban a aquellos que se erigían como «sacerdotes de la legislación», que trataban «de encerrar el Código Civil en el Sancta sanctorum para que nadie lo profane». ${ }^{96}$ Por el contrario «un código debe ser una ley viva y no un peso muerto para una sociedad y debe adaptarse al desarrollo espontáneo de las agrupaciones humanas». ${ }^{97}$

Para ello no se debían consagrar «como inmutables principios abstractos de derecho que pueden entorpecer el bienestar colectivo». ${ }^{98} \mathrm{La}$ "majestuosidad del código» no podía «subsistir ante la verdad-ambiente». ${ }^{99}$ Se trataba de introducir en el ordenamiento de fondo, «el gran concepto social»: ${ }^{100}$ de abrir «una brecha» al «viejo código de Vélez» a través de «nuevas relaciones entre propietarios e inquilinos, de nuevas ideas, de nuevos conceptos sobre la propiedad» ${ }^{\mathbf{1 0 1}}$ ya que aquél no podía «ser una muralla que contenga la expansión de las relaciones sociales o jurídicas de este pueblo». En definitiva el derecho no podía ni debía «estar cristalizado en los códigos» porque «una ley crista- lizada revela un estancamiento de la sociedad y anuncia su parálisis o su disolución»: ${ }^{102}$

«El derecho ha de ser dinámico, debe seguir el desarrollo natural de la sociedad; y, por el contrario, los códigos contienen el derecho estático, sin aliento, sin vida. Pretender encerrar para siempre el derecho en las páginas de un código, es tan erróneo, tan ilógico y tan absurdo como procurar contener en un molde el desarrollo corporal de la criatura humana. Hay que romper los viejos moldes jurídicos, hay que reformar o substituir las leyes arcaicas, los códigos anacrónicos, que ya no responden a las modernas relaciones sociales y a los nuevos ideales de justicia y equidad. La estructura económica de una nación determina su superestructura jurídica; las relaciones de la producción y del cambio de riqueza influyen sobre los conceptos jurídicos y sobre las relaciones de derecho, y como aquellas cambian y progresan continuamente, justo es que las leyes sigan el curso de su evolución». ${ }^{103}$

Para ello los legisladores no debían atarse a «escrúpulos jurídicos», ${ }^{104}$ guiarse "por los principios absolutos del derecho» o apegarse «al espíritu y a la letra de la ley»; debía dirigir su criterio en la obra de legislación colectiva y social «el buen sentido», el «sentido común del buen vecino, mucho más que el principio jurídico del derecho absoluto». 105

\section{La crítica de un derecho de propiedad} absoluto

En concreto, los proyectos presentados implicaban revisar, confrontándolos con la realidad, las concepciones jurídicas liberales plasmadas en los
94 Congreso nacional (1920 III) 676

95 Dicho término es utilizado por el diputado Maidana.

96 Discurso del senador del Valle Iberlucea, Congreso nacional Senadores (1920 II) 76.

97 Del discurso del senador del Valle Iberlucea, Congreso NACional Senadores (1920 II) 76 .

98 Del discurso del diputado Ferreyra, Congreso nacional (1920 I) 256.
99 Del discurso del diputado Roydero, Congreso nacional (1920 III) 780.

100 Del discurso del diputado Ferrarotti, Congreso nacional (1920 III) 874.

101 Del discurso del diputado Dickmann, Congreso nacional (1920 III) 793.

102 Del discurso del senador del Valle Iberlucea, Congreso nacional Senadores (1920 II) 72.

103 Congreso NACIONAL Senadores (1920 II) 72 .
104 Del discurso del diputado de Tomaso, Congreso nacional (1920 III) 742.

105 Del discurso del diputado Dickmann, Congreso nacional (1920 III) 866. 
códigos decimonónicos, que giraban principalmente en torno al propietario como poseedor de un derecho absoluto sobre la cosa. ${ }^{106}$ Una serie de mecanismos jurídicos, fundamentalmente el principio de la pacta sunt servanta, le permitía a éste mantener una situación de privilegio en amplias esferas sociales y económicas. Las transformaciones económicas y sociales de fines del siglo XIX y principios del XX, y las corrientes de pensamiento que las acompañan, ponían en crisis esta concepción, reclamando, entre otras cosas, una mayor limitación del derecho de propiedad por parte del Estado. ${ }^{107}$

Ese derecho «sagrado» de propiedad, absoluto y exclusivo, "principio básico» del ordenamiento legal, era el defendido por aquellos que resistían la reforma, y encuentra en el discurso del diputado Julián Maidana sus expresiones esenciales:

«... frente a estas disposiciones claras de nuestro derecho positivo que garantes [sic] a cada propietario el libre uso, goce o disposición de su propiedad, ¿ puede dictarse una ley, como lo pretenden los reformistas, que prive al propietario de un bien raíz percibir todos los frutos que esa propiedad pueda producir? No, señores diputados, porque esa ley vendría no solamente a alterar, sino a destruir en sus fundamentos el derecho sagrado de usar y gozar de la propiedad, lo que no puede hacer el congreso, de acuerdo con el artículo 28 de la constitución». ${ }^{108}$

Los legisladores que apoyaban las medidas esgrimían como argumento principal la posibilidad de reglamentar cualquier derecho, incluso el de propiedad, facultad que se confería al Estado en el ordenamiento vigente: «Yo no necesito recordar a los señores diputados todas las reglamentaciones que ese derecho, que el señor diputado cree que es absoluto, ha sufrido, hasta en el propio código civil, cuerpo eminentemente conservador construido sobre una concepción de la familia y de la propiedad que no tiene, por cierto, nada de revolucionaria». ${ }^{109}$ Con estas medidas se intentaba ir más allá: si esas restricciones en su momento fueron favorables a los propietarios, ¿ por qué no establecerlas ahora a favor del locatario? ${ }^{\mathbf{1 1 0}}$

En el fondo, más allá de los tópicos jurídicos invocados, se advertía una disímil valoración, tanto social como económica, del peso y significado de ese propietario individualista sostenido en la estructura del código:

«... no me inquietan los escrúpulos que el presente proyecto de ley suscite entre los hombres apegados a la vieja legislación, porque sé que la vida ha borrado del jus utendi et abutendi del bárbaro concepto romano de la
106 Clavero (1998); Tarello (1988) 55-57.

107 Costa (2004)

108 También interesa la descripción que hace del propietario siguiendo los viejos cánones decimonónicos: «En efecto, señores diputados; conservar la vida, trabajar y adquirir bienes son derechos esenciales del hombre, inseparables de su condición natural y libre. Por el trabajo el hombre se hace propietario y se pone en condiciones de cumplir su propio destino en la vida social. El trabajo es, pues, un derecho y una condición de la vida, por cuyo ejercicio el hombre provee a las necesidades de su ser físico y moral, y la acción del trabajo aplicada a la propiedad es la base fundamental del progreso material y moral de la humanidad. Por eso nuestra constitución ha reconocido y proclamado entre los derechos de que está investida la personalidad humana, como preexistentes a la constitución y al gobierno del estado, el derecho a la vida, el derecho de trabajar, el de libertad, igualdad y propiedad, derechos que deben ser ejercitados de conformidad a las leyes que reglamenten su ejercicio, sin que esas leyes reglamentarias puedan alterarlos en ningún momento». Congreso NACIONAL (1920 III) 721.

109 Discurso del diputado de Tomaso, Congreso nacional (1921 I) 480. «Dice la nota que Vélez puso al pie del 2508 , invocadísima por ambas posturas: ‘Cuando establecemos que el dominio es exclusivo, es con la reserva de que no existe con este carácter sino en los límites y bajo las condiciones determinadas por la ley; por una consideración esencial a la sociedad: el predominio, para el mayor bien de todos y de cada uno, de los intereses generales y colectivos sobre el interés individual»».

110 «El codificador ha establecido restricciones y límites al dominio; pero, como él lo dice en la nota, esos límites y esas restricciones tenían en cuenta principal si no exclusivamente, el interés del propietario. Algunas de esas restricciones y limitaciones se explican por razones de orden público, sin duda, pero aun esas mismas fueron, en el concepto del codificador, establecidas en beneficio del propietario. (...) ¿ Por qué no establecer, también, en el código restricciones al dominio en beneficio de los arrendatarios, si es que las medidas que proponemos pueden calificarse de tales?» Discurso del diputado de Tomaso, Congreso NACIONAL (1920 III) 738. 
propiedad, el derecho de abusar y que un nuevo derecho se abre paso en la humanidad nueva». ${ }^{111}$

Frente a una imagen estática e idealizada del propietario, ${ }^{\mathbf{1 1 2}}$ se opone otra descripta en términos crudos y peyorativos. Se insistía en que la forma de explotación de la propiedad privada hacía imposible el bienestar colectivo y perturbaba la paz social; ${ }^{113}$ donde los propietarios que no habían contribuido al progreso de la colectividad en ninguna forma, percibían intereses fabulosos que estipulaban confiados en la situación de especial debilidad de los deudores, ${ }^{\mathbf{1 1 4}}$ especialmente de los inquilinos. ${ }^{115}$ Remarcaban que esa "propiedad vive a expensas del crecimiento de la ciudad, [y] sus dueños no hacen nada y capitalizan ingentes fortunas con el simple aumento del valor de la tierra», consistiendo ese valor en "utilidades no ganadas por el trabajo acumulado». ${ }^{116}$

\section{La función social de la propiedad}

Llegamos así a la consideración de un tópico cuya articulación en el debate, si bien aparece escasamente invocado, reviste aristas particulares que resulta interesante analizar.

Se ha señalado que las primeras apariciones de este concepto y su consiguiente introducción en el vocabulario jurídico argentino estarían relacionadas con las conferencias que Leon Duguit dictó en la Facultad de Derecho de la Universidad de Buenos Aires en 1911. ${ }^{117}$ En concreto, la sexta conferencia se refería justamente a «La propiedad: función social». El jurista francés advertía sobre la transformación general de la concepción jurídica de la propiedad donde ésta «deja de ser el derecho subjetivo del propietario para convertirse en la función social del poseedor de la riqueza». ${ }^{\mathbf{1 1 8}}$

En el debate que analizamos, si bien existen referencias al «fin social», al «bienestar colectivo», al "gran concepto social», al «interés general de la sociedad», no encontramos una descripción extrema de este tópico en los términos que hiciera Duguit. Es verdad que contra el carácter absoluto del derecho de propiedad se esgrimía que «la creación, el acrecentamiento y la estabilidad de la propiedad privada no son obra sólo del individuo aislado, sino del conjunto de los hombres, y de la sociedad en que convive; a quien debe por consiguiente el propietario una parte de sus beneficios, ya que ella es quien le asegura su legítimo goce»; pero esto no significaba negarla como derecho sino someterla a «legítimas reglamentaciones, que sin afectarla en su esencia, la hagan realmente eficaz al fin social que está llamada a desempeñar». ${ }^{119}$

El diputado Arturo Bas, que se llama a sí mismo «conservador», es quien lo utiliza:

«La propiedad desempeña una función social, y dentro de la evolución impuesta por las necesidades, su legislación debe también modificarse. Es necesario no equivocarse, porque tarde o temprano esa transformación ha de venir, y los que nos consideramos conservadores - entre los que yo me encuentro en primer término debemos tener una noción clara de la situación y no pretender encerrarnos en principios absurdos, por lo absolutos, para negar al pueblo, en su base, lo que reclama con derecho y en justicia, porque precisamente las transformaciones evidentes de los conceptos y valores económicos y sociales exigen también una interpretación dis-
111 Del discurso del diputado Tamborini, Congreso nacional (1920 I) 216.

112 «Señores diputados. Nosotros no tenemos por qué atacar a los propietarios. Ellos han exteriorizado y ofrecido al usufructo de todo el mundo el producto de su trabajo honesto; han levantado las casas y con ello han hecho obra de civilización, permitiendo que el pueblo viva la vida moderna en que estamos desenvolviéndonos. Si no fuera por el esfuerzo de esos capitalistas, grandes y pequeños, viviríamos como los lanceros desnudos y bravíos del desierto, en los pajonales, en las llanuras, en las hondonadas de la tierra o al abrigo de los montes». Discurso del diputado Maidana, Congreso NACIONAL (1920 III) 871 .

113 Discurso del diputado Tamborini, Congreso nacional (1920 I) 216.

114 Discurso del diputado Anastasi, Congreso nacional (1920 III) 771.

115 «Porque la falla que existe en nuestro código civil, contra la cual se va y que ha creado la situación actual, es esa omnipotencia del propietario que dice al inquilino: usted me paga tanto o usted se va; y por lo común ese propietario aguza su interés a medida que la situación del inquilino la va viendo en florecimiento». Discurso del diputado Ferrarotti, Congreso nacional (1920 III) 876.

116 Discurso del diputado Molina, Congreso nacional (1920 I) 318.

117 LeVaGgi (2007); LeON (1952).

118 Duguit (1920) 167.

119 Discurso del diputado Bas, Congreso NACIONAL (1920 III) 684. 
tinta de los principios absolutos que han regido hasta hoy el derecho de propiedad». ${ }^{\mathbf{1 2 0}}$

Pero su ausencia, sobre todo en las argumentaciones socialistas, fue advertida por la diputación conservadora. ${ }^{\mathbf{1 2 1}}$

Por otro lado, el senador socialista del Valle Iberlucea defiende la función social de la propiedad así como los proyectos sancionados por la Cámara de Diputados apoyándose no tanto en la autoridad de Duguit, a quien simplemente nombra, sino más bien en los argumentos que un año atrás había desarrollado a favor del concepto el profesor de Economía Política en la Facultad de Derecho de Buenos Aires, Juan José Díaz Arana. ${ }^{122}$ Su intención era demostrar los nuevos rumbos que este tópico había tomado en nuestra cultura jurídica: «Estas ideas han penetrado en los medios democráticos y conservadores y han sido recogidas por autores y civilistas de distintas escuelas y aun por los hombres políticos de tendencias conservadoras». ${ }^{123}$

9 La crítica del principio de libertad de contratar fundado en una igualdad «ficticia»

Otro «principio básico e inmutable» que atacaba las medidas propuestas era la libertad de contratar, «expresión genuina de la libertad individual». ${ }^{\mathbf{1 2 4}}$ Este principio, tan caro al derecho decimonónico, se fundaba, a su vez, en la pretendida igualdad jurídica de las partes contrayentes.

Las críticas a este postulado, de diversos tonos, se centraban en remarcar, justamente, el carácter ficticio de esta construcción: ${ }^{\mathbf{1 2 5}}$ que se trataba de una «mentira convencional»; ${ }^{\mathbf{1 2 6}}$ que la realidad era la desigualdad entre locadores y locatarios y que las reformas intentaban recomponer la misma: ${ }^{\mathbf{1 2 7}}$
«Pero esta es la ficción [la igualdad entre locador y locatario], señor presidente, no es la realidad: lo real, lo positivo y lo evidente, es que en las relaciones entre propietarios e inquilinos existe, por regla general, una desigualdad análoga a esa desigualdad que existe en las relaciones entre los empresarios y los trabajadores». ${ }^{\mathbf{1 2 8}}$

La pretendida igualdad jurídica resultaba, en definitiva, para algunos, una construcción que carecía de asidero en la realidad:

«El señor diputado por la provincia de Buenos Aires, al hacer su réplica jurídica, ha hablado de un inquilino ideal colocándose en un punto de vista que yo llamaría - para darle un nombre de derecho abstracto, de derecho puro, de un inquilino que tuviera libertad absoluta de contratar con el propietario cuya casa alquila. Pero no es esa la realidad: el inquilino real es otro». ${ }^{129}$

Quizás fue el diputado Anastasi quien mejor expresó las intenciones profundas de las modificaciones que se llevaban adelante: «... yo entiendo que el principio de la igualdad jurídica de las partes no se altera $[\ldots]$ y en todo caso [...] se ha alterado tanto tiempo en beneficio del propietario que bien valdría mudar, aunque sea transitoriamente, la situación actual». ${ }^{130}$

\section{La validez de las leyes de emergencia}

Algunas de las medidas proyectadas, en especial la fijación legal del precio de la locación, suscitó en el recinto un intenso debate, sobre el significado y valor de una legislación de emergencia, frente a la existencia de un orden constituido de la República,
120 Congreso nacional (1921 I) 485.

121 «Yo hubiera deseado más bien que el señor diputado Dickmann, lo mismo que el señor diputado de Tomaso, en sus eruditos discursos hubieran invocado como principio general eso que ellos preconizan en su escuela: la función social de la propiedad. Felizmente no han tocado ese punto». Congreso nacional (1920 III) 862.

122 Congreso nacional Senadores (1920 II) 73. Se refiere a la exposición que Díaz Arana presentó en el Congreso de la Habitación, celebrado en el
Museo Social en 1920. Sobre la influencia de la cátedra de Economía Política en la ciencia jurídica argentina ver ZimmermanN (1995) 83-94; sobre la actuación de Juan José Diaz Arana ver ZimmermanN (2008) 184.

123 Congreso NACIONAL Senadores (1920 II) 73 .

124 Discurso del diputado Maidana, Congreso nacional (1920 III) 721. Discurso del diputado Sánchez Sorondo, Congreso NACIONAL (1920 III) 850 .
125 Discurso del diputado Dickmann, Congreso nacional (1920 III) 866.

126 Discurso del diputado Molina, Congreso nacional (1920 I) 318.

127 Discurso del diputado Dickmann, Congreso nacional (1920 III) 847.

128 Discuros del senador del Valle Iberlucea, Congreso nacional Senadores (1920 II) 76.

129 Discurso del diputado de Tomaso, Congreso nacional (1920 III) 867.

130 Congreso NaCional (1920 III) 868. 
cuya expresión jurídica se centraba en la constitución y el código. ${ }^{131}$

Estas medidas, que como veremos encontraban su modelo fundamental en las legislaciones sancionadas principalmente en Europa, se justificaban principalmente ante la «presencia de lo anormal», ${ }^{\mathbf{1 3 2}}$ por "graves y urgentes exigencias del momento actual» debidas al «encarecimiento inaudito de la vivienda de situaciones» ${ }^{\mathbf{1 3 3}}$ que limitaban con lo ilícito: la «extorsión», ${ }^{134}$ la «explotación» y la «estrangulación de las clases trabajadoras». ${ }^{135}$

La anormalidad se concebía como una alteración «temporaria» de ese orden que reclamaba una intervención «necesaria y urgente» de los poderes públicos. Así por lo menos lo entendía el diputado Víctor Molina, «fervoroso creyente en el libre cambio»: ${ }^{136}$ «desde la guerra hasta hoy la ley de la oferta y de la demanda ha sido sustituida en el hecho por el sistema de acaparamiento que, en todos los países del mundo, ha provocado una legislación represiva». ${ }^{\mathbf{1 3 7}}$

Para otros, esa «emergencia» implicaba la pasividad de los poderes públicos para llevar adelante las reformas que exigían los tiempos. ${ }^{138}$ Así lo sostenía el diputado Justo: «Si ahora esto aparece propuesto como medida de emergencia, no es sino por la pereza consuetudinaria del parlamento argentino para la legislación necesaria, para la legislación orgánica. Pero urge absolutamente llevar una reforma inmediata al capítulo de la locación de nuestro anticuado código civil». ${ }^{139} \mathrm{O}$ también el senador del Valle Iberlucea: «En nombre de viejas doctrinas económicas, señor presidente, los poderes públicos no pueden cruzarse de brazos y decir, como los fisiócratas del siglo XVIII: ¡ laissez faire, laissez passer! El Estado debe intervenir ...» 140

La comisión de legislación fue muy escrupulosa, como lo señala uno de sus miembros, el diputado Mora y Araujo, al distinguir en dos proyectos de ley, como ya se ha visto, aquellas propuestas de modificación del código civil de las medidas que revisten un «carácter transitorio y ocasional, que necesariamente habían de revestir las que se refieren al encarecimiento de la vivienda». ${ }^{\mathbf{4 1}}$

Pero una frase de éste, dicha al pasar, nos enfrenta al verdadero alcance y significado de esta legislación de emergencia. Afirmaba el diputado Mora y Araujo que se trataba «de una cuestión de hecho» que no requería «mayor ciencia jurídica». ${ }^{\mathbf{1 4 2}}$ Esta afirmación, expresada en un contexto de fuerte crítica al contenido y forma de expresión del derecho vigente, dejaba entrever que para algunos existía un orden que se estaba transformando y que los moldes rígidos de la «ciencia jurídica» tradicional no lo podían contener. No importa ahora que en ese momento se entendiesen esos hechos como algo pasajero o temporario. Lo cierto era que de esta manera, mediante esta construcción, se permitió arribar a soluciones jurídicas que alteraban los principios básicos de un ordenamiento considerado inmutable hasta hace muy poco.

De ahí que aquellos que estaban en contra de la modificación del código civil se preocupasen especialmente de determinar el acotado espacio de esta legislación de emergencia, permitiendo de esta manera una válvula de escape del ordenamiento jurídico, sin que esos principios se incorporasen a la ley de fondo que era de carácter «permanente»:

«Preocupado también yo del asunto en debate, preocúpame que tratemos de resolverlo modificando el código civil. Pienso que debemos resolver el asunto y que podemos resolverlo sin tocar al código. No es prudente introducir en los códigos fundamentales, encargados de regir la vida normal de la sociedad, ciertas concepciones recientes, de emergencia, como ha dado en llamárselas y como tienen que ser las medidas que adoptemos. Eso no lo aconseja la doctrina. Bajo la influencia de situaciones extraordinarias - que obedecen a causas complejas, complejísimas, a un momento económico que ha escapado a toda provisión - lo que corresponde, a mi juicio, es dictar una ley especial, suspendiendo por tiempo indetermi-
131 Halperín Donghi (1999) 183-196; Bidart Campos (1997) 349-359.

132 Discurso del diputado Molina, Congreso nacional (1920 I) 317.

133 Discurso del diputado Molina, Congreso nacional (1920 I) 316.
134 Discurso del diputado Del Valle, Congreso nacional (1920 I) 277. 135 Discurso del diputado Molina, Congreso nacional (1920 I) 317. 136 Halperín Donghi (1999) 188.

137 Congreso NaCiOnal (1920 I) 317. 138 Halperín Donghi (1999) 183.
139 Congreso nacional (1920 III) 772.

140 Congreso nacional Senadores (1920 II) 69 .

141 Congreso nacional (1920 III) 676.

142 Discurso del diputado Mora y Araujo, Congreso nacional (1920 III) 679. 
nado, pero no derogando, la regla del código para los tiempos normales. Esta es la misión de las leyes especiales, de emergencia, necesarias para una situación determinada; pero no la de los códigos cuya vida ha de regir lo permanente y no lo transitorio». ${ }^{143}$

11 La referencia al derecho extranjero como legitimador de las propuestas reformistas

Las discusiones se hicieron eco de las experiencias legislativas de otros países, especialmente europeas. Las medidas legislativas se encontraban respaldadas por «el ejemplo que han proporcionado las naciones-modelos desde el estallido de la guerra: en todas ellas el Estado no ha vacilado en afrontar las emergencias económicas modificando el funcionamiento de la economía por sucesivos actos de imperio». ${ }^{144}$

Se invocó, incluso en detalle, antecedentes legislativos de distintos países europeos, como Francia, Inglaterra, España y Bélgica. ${ }^{145}$ También se presentó como modelo de modernidad tanto las soluciones que, para la materia en cuestión, brindaba el código civil alemán, ${ }^{\mathbf{1 4 6}}$ como las opiniones de autores extranjeros como Ihering, Savigny, ${ }^{147}$ Posada, Menger, Saleilles, Duguit, Salviolli y D'Aguanno. ${ }^{148}$

No nos interesa en este estudio comparar las soluciones arribadas en nuestro país con aquellas suscitadas en el extranjero. Más bien nuestra atención se enfocará en analizar la función que tuvo ese «derecho comparado» en el debate, como lugar desde donde se construye una determinada solución jurídica para un problema local. ${ }^{149}$
Resulta interesante observar que la mayoría de los legisladores calificaban el problema de la falta de vivienda y del alza de los precios del alquiler como un fenómeno «universal», lo que legitimaría no solo un análisis local de la situación, sino una mirada más allá de nuestro ordenamiento vigente. ${ }^{150}$ Ahora bien, esa «universalidad» se identificaba - y acotaba, en realidad - en el imaginario de nuestros legisladores, con la situación europea, a la cual se referían constantemente. Para algunos, incluso, esta identidad no se daba solamente en el plano de los hechos, sino también del derecho: si nuestros códigos eran copia de aquellos que imperaban en el viejo mundo, ¿qué obstáculo había para adoptar esa legislación que algunos tercamente rechazaban?:

«En esos países hay códigos civiles idénticos al nuestro, como que han sido hechos sobre el modelo del código de Napoleón. También hay allí un orden constitucional, y sin embargo, no se ha encontrado que ellos fueran óbice para dictar esa legislación» ${ }^{151}$ [...] Pues bien; en países que tienen la misma organización jurídica y política que la nuestra, en países que poseen un código civil del cual el nuestro no es sino una simple copia, se han dictado medidas iguales bajo el imperio de circunstancias o necesidades más apremiantes que las nuestras, sin duda, pero iguales en lo que tienen de fundamental. A ningún juez se le ha ocurrido decir que fueran atentatorias del derecho de propiedad. ${ }^{152}$

En este sentido, las leyes europeas no eran solo una posibilidad, un modelo, sino una necesidad impuesta por la evolución jurídica, una forma de
143 Discurso del diputado Quirós, Congreso nacional (1920 IV) 338. Esta preocupación también la asume la Corte Suprema en el fallo ya citado. 144 Halperín Donghi (1999) 188.

145 Por ejemplo: Discurso del diputado Tamborini, Congreso nacional (1920 I) 216; del diputado Anastasi, Congreso nacional (1920 III) 771, del diputado Ortiz, Congreso NACIONAL (1920 III) 859; del senador del Valle Iberlucea, Congreso NACIONAL Senadores (1920 II) 65.

146 Lo invoca el diputado de Tomaso para demostrar que ese código había superado un derecho privado centrado en la figura del propietario.

Congreso nacional (1920 III) 736.

También el senador del Valle Iberlucea, Congreso nacional Senadores (1920 II) 76.

147 Congreso nacional Senadores (1920 II) 72 .

148 Congreso nacional Senadores (1920 II) 72 .

149 Ya se ha señalado que uno de los objetivos de este proyecto es analizar las visiones que se tenían del derecho extranjero en el período de estudio y, fundamentalmente, con este análisis queremos refutar aquellas concepciones de los fenómenos de circula- ción de ideas y modelos jurídicos como meros transplantes legales, donde los supuestos ordenamientos jurídicos receptores obran con total pasividad.

150 Que, como se ha visto, se consideraba insuficiente para brindar la solución justa que se buscaba.

151 Discurso del diputado de Tomaso, Congreso nacional (1920 III) 726.

152 Discurso del diputado de Tomaso, Congreso nacional (1921 I) 482. 
colocarnos en «una corriente de legislación general en el mundo». ${ }^{\mathbf{1 5 3}}$ Frente a este argumento, nuestro ordenamiento, nuestros "principios básicos», aparecían arcaicos y obsoletos. ${ }^{\mathbf{1 5 4}}$

Pero no era esta una mirada pacífica. Para muchos, por el contrario, «nuestra situación no es igual a la de los países extranjeros» ${ }^{\mathbf{1 5 5}}$ y esa «costumbre» de copiar sin más lo extranjero podía resultar «peligrosa». ${ }^{\mathbf{1 5 6}}$

Se necesitaba poner una valla a las «nuevas corrientes», ${ }^{157}$ a «cualquier reforma de nuestras leyes orgánicas elaboradas en nombre de las nuevas orientaciones o en la tendencia de imitar a lo que se hace en otras partes, aunque con ello se disloquen las bases de nuestra organización política, social y económica». 158

Se reclamaba entonces un «criterio argentino» en la actividad legislativa:

«He citado la legislación extranjera, y siendo esta una de las primeras veces que hablo en esta honorable cámara debo hacer una especie de declaración de principios. A mí no me entusiasma en forma alguna el espíritu de imitación de la legislación extranjera, ese afán de copia exagerada de todo lo que allá se legisla y que encuentro en cierto modo en el parlamento de mi país; ese absolutismo de concepto que implica aceptar como bueno todo lo que se legisla en el exterior. Ellas podrán serlo de acuerdo con las modalidades y las idiosincrasias de esos pueblos; pero no siempre lo serán para nosotros. Yo creo, como se ha dicho aquí en otras ocasiones, que debemos legislar en presencia de nuestros propios problemas en ambiente argentino y con criterio argentino». ${ }^{159}$
En síntesis, para esta postura, la tarea resultaba mucho más compleja: "Así como no es posible en el estudio de la legislación comparada recoger de cualquier parte las iniciativas para trasladarlas a nuestro país, así también debemos tener el concepto de la localización de los conceptos jurídicos para poder aplicarlos de forma inteligente y civilizadora a nuestro modo de ser». ${ }^{\mathbf{1 6 0}}$

\section{Consideraciones finales}

Identificar el presupuesto ideológico de las construcciones jurídicas esgrimidas en este debate, tan caras a la cultura jurídica del período que se estudia; visualizar dichas construcciones, no ya en la aséptica descripción académica de la lección de derecho o del tratado, sino en el fragor de la discusión parlamentaria, revelan la relatividad y contingencia de las mismas, en definitiva, su historicidad.

A la luz del debate analizado, las leyes sancionadas pueden ser concebidas no tanto como «la voluntad del legislador», sino como el consenso logrado en un momento determinado en base a un profundo desacuerdo en torno a cuál debía ser el rol del Estado y la vigencia de los derechos frente a las circunstancias concretas que se desplegaban en nuestro país. La prevalencia de unas argumentaciones sobre otras no reside tanto en la lógica intrínseca de las mismas, sino en el contexto en que éstas se desenvuelven: la emergencia económica, el agotamiento de un modelo político y la democratización del mismo.

Un derecho inmutable expresado en constituciones y códigos, un propietario absoluto que hace
153 Discurso del diputado Mora y Araujo, Congreso naCional (1920 III) 681.

154 Remitimos a lo que se ha dicho sobre este tema en el acápite sobre la reforma del código.

155 Discurso del diputado Quiros, Congreso NACIONAL (1920 IV) 338. También el senador Garro. «Y bien, señor presidente. Por el hecho de que aquellos países azotados por la guerra más colosal que se conoce, envueltos aún en las consecuencias de la catástrofe que amenaza su propia existencia, apelen a recursos heroicos y supremos, ¿ significa que nosotros, por espíritu de imitación, debamos hacer lo mismo? Y aunque así fuera, ¿ cómo se explicaría que nosotros pretendiéramos ir mucho más lejos y llegar a extremos a que aquellos países no han querido llegar todavía?»

Congreso NACIONAL Senadores (1920 II) 80 .

156 Así lo advierte, para rebatir la idea, el 158 diputado de Tomaso: «Las leyes de emergencia sobre esta materia, sancionadas en Europa, de las que tanto se ha hablado, tienen un alcance que ha sido exagerado, sin duda porque se conocían poco, dentro del recinto y aun fuera de él. La gente afuera tiene la impresión de que en Europa se han sancionado sobre esta materia medidas catastróficas, y es bueno señalar en pocas palabras en qué consisten en realidad y cuál es su carácter fundamental». CONGRESO NACIONAL (1920 III) 734 .

157 Congreso nacional (1920 I) 360

58 Del discurso del senador Garro, Congreso NACIONAL Senadores (1920 II) 78 .

159 Discurso del diputado José Heriberto Martínez, Congreso NACIONAL (1920 III) 762 .

160 Congreso nacional (1920 III) 876. 
y deshace es la expresión jurídica de un orden que se ve asimismo inamovible. La legislación de emergencia aparece, así, como una válvula de escape de ese orden "permanente», como una posibilidad de contener jurídicamente en sí mismo lo que se considera «anormal», «pasajero», «transitorio", aunque, de alguna forma, para ello deban sacrificarse algunos de sus "principios básicos».

La defensa de la «función social de la propiedad» tiene un rol instrumental en las discusiones legislativas. Su invocación desde las posturas «conservadoras» asegura por un lado la salvaguardia del orden preexistente en cuanto a la no «desnaturalización» del derecho de propiedad. Por el otro, legitima la acción de un Estado que para afrontar los conflictos sociales precisa limitar y regular el ejercicio de esos derechos, en aras del «bienestar general».

Las referencias al derecho extranjero no solo funcionan como modelo a seguir sino, en algunos casos, como presupuesto legitimador de las reformas: interesa demostrar que las soluciones proyectadas son jurídicamente viables. Por el contrario, para otros, la experiencia jurídica foránea reviste el carácter de peligroso: no solo resulta ajena a la realidad nacional, sino que viene de la mano de «nuevas corrientes», o de nuevos presupuestos ideológicos que pueden alterar los fundamentos tradicionales del orden jurídico de la República.

De todos modos, en uno y otro sentido, no podemos afirmar que esa referencia al derecho comparado resulte una recepción pasiva del derecho extranjero. El mismo se inserta en un intenso proceso de creación de la solución jurídica, donde él es simplemente un elemento más a considerar y consensuar.

\section{Bibliografía}

- Altamirano, Carlos (2004), Entre el naturalismo y la psicología: el comienzo de la ciencia social en la Argentina, en: Neiburg, Federico, Mariano Plotkin (compiladores), Intelectuales y expertos. La constitución del conocimiento social en la Argentina, Buenos Aires: Paidós, 31-65

- Barbé, Carlos, Mabel Olivieri (1992), Sociología, Storia Sociale e Scienza Politica in Argentina sino alla crisi del positivismo, en: Barbano, F., C. Barbé, M. Berra, M. Olivieri, E. Koch-Weser Ammassari, Sociologia, storia, positivismo. Messico, Brasile, Argentina e l'Italia, Milano: Franco Angeli, 237-473

- Bibiloni, Juan Antonio (1911), Discurso de colación de grados de 1897, en: Discursos Académicos, Facultad de Derecho y Ciencias Sociales de la Universidad de Buenos Aires, Tomo Primero (1880-1910), Buenos Aires, 209-216

- Bidart Campos, German J. (1997), Manual de la Constitución refomada, T. II, Buenos Aires: Ediar

- Botana, Natalio (1998), El orden conservador. La política argentina entre 1880 y 1916, Nueva edición con estudio preliminar, Buenos Aires: Editorial Sudamericana

- Botana, Natalio, Ezequiel Gallo (2007), De la República posible a la República verdadera (1880-1910), Biblioteca del pensamiento argentino, Tomo III, 2a edición, Buenos Aires: Emecé

- Cesano, Jose Daniel (2012), Redes intelectuales y recepción en la cultura jurídico penal de Córdoba (1900-1950), en: Rechtsgeschichte 20 (2012) 156-169

- Clavero, Bartolomé (1998), Les Domaines de la Propriété, 1789-1814: Propiedades y Propiedad en el Laboratorio Revolucionario, en: Quaderni Fiorentini per la Storia del Pensiero Giuridico Moderno 27 (1998) 268-378

- Clavero, Bartolomé (2007), El Orden de los Poderes. Historias Constituyentes de la Trinidad Constitucional, Madrid: Editorial Trotta

- Congreso nacional, Diario de sesiones de la Cámara de Diputados, Año 1919, Tomo I, Sesiones ordinarias, Buenos Aries, 1919

- Congreso nacional, Diario de sesiones de la Cámara de Diputados, Año 1920, Tomo I, Sesiones ordinarias, Buenos Aries, 1920

- Congreso nacional, Diario de Sesiones de la Cámara de Senadores, Año 1920, Tomo II, Sesiones extraordinarias, Buenos Aires, 1921

- Congreso nacional, Diario de Sesiones de la Cámara de Diputados, Año 1920, Tomo III, Sesiones ordinarias, Buenos Aires, 1920

- Congreso nacional, Diario de Sesiones de la Cámara de Diputados, Año 1920, Tomo IV, Sesiones ordinarias, Buenos Aires, 1920

- Congreso nacional, Diario de Sesiones de la Cámara de Diputados, Año 1921, Tomo I, Sesiones ordinarias, Buenos Aires, 1921

- Costa, Pietro (2004), Derechos, en: Fioravanti, Maurizio (ed.), El Estado moderno en Europa, Madrid: Editorial Trotta

- Dellepiane, Antonio (1908), La filosofía jurídica en la formación del jurista. Conferencia inaugural del curso de Filosofía del Derecho, en: Nosotros 10 y 11 (mayo y junio de 1908), 235-245. También online: http://www.cervantesvirtual.com/obra-visor/ nosotros--6/html/027ed8f4-82b2-11df-acc7-002185ce6064_3.html\#I_3_

- Díaz Couselo, José María (2007), Presentación, en: Tau Anzoáté-̄ui (2007) 223-227 
- Duguit, León (1920), Las Transformaciones generales del Derecho privado desde el Código de Napoleón, Traducción de Carlos G. Posada, Segunda edición corregida y aumentada, Madrid: Francisco Beltran

- Garcia Canclini, Nestor (2010), Culturas híbridas. Estrategias para entrar y salir de la modernidad, Nueva Edición, Buenos Aires: Paidós

- García Sebastiani, Marcela (2008), Interlocutores y escenarios del liberalismo reformista español en Argentina, en: García Sebastiani, Marcela, Fernando Del Rey Reguillo (eds.), Los desafíos de la libertad.Transformación y crisis del liberalismo en Europa y América Latina, Madrid: Biblioteca Nueva 349-372

- Grossi, Paolo (1992), La propiedad y las propiedades. Un análisis histórico, Madrid: Editorial Civita

- Halperín Donghi, Tulio (1999), Vida y muerte de la república verdadera, Buenos Aires: Ariel

- Hespanha, Antonio Manuel (2002), Cultura Jurídica Europea. Síntesis de un Milenio, Traducción de Isabel Soler y Concepción Valera, Madrid: Editorial Tecnos

- Lecuona,Diego Eugenio (1993), Orígenes del problema de la vivienda, Tomos 1 y 2, Buenos Aires Centro Editor de América Latina

- Leiernur, Jorge Francisco (2000), La construcción del país urbano, en: Zaida Lobato, Mirta (directora), Nueva Historia Argentina, tomo 5, Buenos Aires: Editorial Sudamericana, 407-463

- Leiva, David Alberto (1988), El Código civil como objeto didáctico en la Argentina a fines del siglo XIX, en: Revista de Historia del Derecho 16 (1988) 321-330

- Leon, Pedro (1952), El derecho de propiedad como función social, en: Revista jurídica de Córdoba, enero-marzo, año 4, nº 13 (1952), 5-29

- Levaggi, Abelardo (2007), Ideas acerca del derecho de propiedad en la Argentina entre 1870 y 1920, en: Revista electrónica del Instituto de Investigaciones Ambrosio L. Gioja, Año 1, Número 1, Invierno 2007: http://www.derecho.uba.ar/revistagioja/ articulos/R0001A001_0006_investigacion.pdf

- Martinez Paz, Enrique (1916), Dalmacio Velez Sarsfield y el Código civil argentino, Córdoba

- Matienzo, José Nicolás (1917), El gobierno representativo federal en la República Argentina, 2a edición, Madrid: EditorialAmérica

- Pugliatti, Salvatore (1954), La proprietà nel nuovo diritto, Milán

- Rodota, Stefano (1986), El terrible derecho. Estudios sobre la propiedad privada, traducción de Luis Díez-Picazo, Madrid: Editorial Civitas

- Polotto, MaríaRosario (2006), Hacia una nueva experiencia del derecho. El debate en torno a la enseñanza práctica del derecho en la Universidad de Buenos Aires a comienzos del siglo XX, en: Revista de Historia del Derecho 34 (2006) 220-227

- Segovia, Juan Fernando (2007), Presentación, en: Tau Anzoátegui (2007) 399-405.

- Serrafero, Mario D. (2003), Las Ciencias Sociales, en: Academia Nacional de la Historia, La Nueva Historia de la Nación Argentina, Tomo X, Buenos Aires: Planeta, 13-37

- Suriano, Juan (1983), Movimientos sociales: La huelga de inquilinos de 1907, Buenos Aires: Centro Editor de América Latina

- Tarello, Giovanni (1988), Cultura giuridica e politica del diritto, Bologna: il Mulino

- Tau Anzó́tegui, Víctor (1977), La codificación en la Argentina (1810-1870). Mentalidad social e ideas jurídicas, Buenos Aires: Imprenta de la Universidad

- Tau Anzoátegui, Víctor (1982), Los comienzos de la fundamentación de las sentencias en la Argentina, en: Revista de Historia del Derecho 10 (1982) 267-371

- Tau Anzoátegui, Víctor (1998), La «cultura del código»: un debate virtual entre Segovia y Sáenz, en: Revista de Historia del Derecho 26 (1998) 539-566

- Tau Anzoátegui, Víctor (2000), Las ideas jurídicas en la Argentina. Siglo XIX, Tercera edición, Nuevamente revisada y ampliada, Buenos Aires: Abeledo Perrot

- Tau Anzoátegui, Víctor (coord.) (2007), Antología del pensamiento jurídico argentino (1901-1945), Tomo I, Instituto de Investigaciones de Historia del Derecho, Buenos Aires

- Tau Anzoátegui, Víctor (2007a), Introducción. Peculiaridad del pensamiento jurídico argentino, en: TAu Anzoátegui (2007) $11-35$

- Tau Anzó́tegui, Víctor (2010), El futuro de la Historia Jurídica en las aulas, Córdoba: Asociación Argentina de Profesores e Investigadores de Historia del Derecho

- Vedia y Mitre, Mariano de (2007), Presentación del Profesor Víctor M. Orlando, fragmento, 1924, en: Tau Anzoategui (2007) 407-408

- Viehweg, Theodor (1986), Tópica y jurisprudencia, Traducción de Luis Díez-Picazo Ponce de León Altea, Madrid: Taurus, Alfaguara S.A.

- Waldron, Jeremy (2005), Derecho y desacuerdos, traducción de José Luis Martí y Águeda Quiroga, Madrid: Marcial Pons

- Watson, Alan (2000), Legal transplants and European Private Law, en: Electronic Journal of Comparative Law vol. 4.4. (December, 2000) http://www.ejcl.org/44/art44-2.html

- Zimmermann, Eduardo (1995), Los liberales reformistas. La cuestión social en la Argentina, 1890-1916, Buenos Aires: Editorial Sudamericana, Universidad San Andrés

- Zimmermann, Eduardo (2008), Transformaciones y persistencia del liberalismo en la Argentina (1890-1930), en: García Sebastiani, Marcela, Fernando Del Rey Reguillo (eds.), Los desafíos de la libertad.Transformación y crisis del liberalismo en Europa y América Latina, Madrid: Biblioteca Nueva, 172-193 